\title{
Catechol versus carboxyl linkage impact on DSSC performance of synthetic pyranoflavylium salts
}

Authors: Ana Lucia Pinto, ${ }^{\mathrm{a}}$ Luis Cruz, ${ }^{\mathrm{b}}$ Vânia Gomes, ${ }^{\mathrm{b}}$ Hugo Cruz, ${ }^{\mathrm{a}}$ Giuseppe Calogero,${ }^{\mathrm{c}}$ Victor de Freitas, ${ }^{\mathrm{b}}$ Fernando Pina, ${ }^{\mathrm{a}}$ A. Jorge Parola, ${ }^{\mathrm{a}}$ J. Carlos Lima ${ }^{\mathrm{a}, *}$

${ }^{a}$ LAQV-REQUIMTE, Departamento de Química, Faculdade de Ciências e Tecnologia, Universidade NOVA de Lisboa, 2829-516 Caparica, Portugal.

${ }^{b}$ LAQV-REQUIMTE, Departamento de Química e Bioquímica, Faculdade de Ciências, Universidade do Porto, Rua do Campo Alegre, 687, 4169-007 Porto, Portugal.

${ }^{c}$ CNR, Instituto per i Processi Chimico-Fisici, Sede di Messina, Salita Sperone, C. da Papardo, I98158 Faro Superiore Messina, Italy.

Keywords: dye-sensitized solar cells, pyranoflavylium dyes, bio-inspired DSSCs

\begin{abstract}
Anthocyanins are the main polyphenolic dyes found in young red wines, which are transformed into more stable structures such as pyranoanthocyanins, during wine ageing and maturation. While anthocyanins practically lose their red color between $\mathrm{pH} 1$ and 5, as a result of the formation of colorless hemiketals, pyranoanthocyanins practically do not change their color intensity. For that they constitute a photosensitizer family with great potential for bio-inspired dye-sensitized solar cells (DSSCs). In this work, a series of pyranoanthocyanin derivatives were designed, synthesized and applied for the first time as dye sensitizers in DSSCs. A relation was established between dye structure and cell efficiency. Specifically, the influence of different linker units, carboxyl and catechol, was studied in terms of their influence in the various parameters related to DSSC efficiency. The presence of the catechol unit was shown to be essential for efficient electron injection of the dye into the $\mathrm{TiO}_{2}$ semiconductor, since carboxylic units showed a deleterious effect in electron injection due to their electron withdrawing character. An overall efficiency of $1.15 \%$ was obtained for the best performing compound, 10-catecholpyrano-3', ,',5,7tetrahydroxyplavylium, with no further optimization.
\end{abstract}

\section{Introduction}

Dye-Sensitized Solar Cells (DSSC), as described by Brian O'Regan and Michael Grätzel ${ }^{1}$, are photovoltaic devices based on the sensitization of wide band-gap semiconductor electrodes with dyes absorbing visible light. These devices have attracted a lot of attention since they display a large flexibility in shape, colour and transparency, compatibility with flexible substrates and a large variety of designs to facilitate market entry. ${ }^{1-3}$ Following the pioneering work of Grätzel, the 
fundamentals of the working principles of DSSCs are basically understood using several types of dyes such as the original ruthenium dyes, ${ }^{4-6}$ but also porphyrins, ${ }^{6-10}$ anthocyanins ${ }^{6-8,11,12}$ and, in recent years, perovskite materials. ${ }^{13-15}$ Until recent years, DSSCs exhibiting higher energy conversion yields were based on functional ruthenium or osmium(II)-polypyridyl complexes, which are expensive and toxic. ${ }^{16}$ In the last years, however, porphyrin dyes and perovskites challenged these compounds in terms of performance, demonstrating the importance of exploring systematically other types of dyes. To this regard, natural anthocyanin dyes and their synthetic derivatives were shown to have promising properties as efficient photosensitizers for DSSCs. ${ }^{6,7,11,17-}$

${ }^{20}$ Kay and Grätzel were probably the first to elucidate the photoelectrochemical behaviour of natural chlorophylls, ${ }^{9}$ while Tennakone and co-workers were the first to use cyanidin (cyanin without the sugar moieties) in a dye sensitized nanocrystalline solar cell. ${ }^{21}$ Grätzel and co-workers applied, for the first time, anthocyanin dyes extracted from blackberries (cyanidin-3-glucoside) in a DSSC displaying a conversion yield of $0.56 \% .^{12}$

Flavylium compounds represent a family of natural, which includes anthocyanins, anthocyanidins and 3-deoxyanthocyanins, responsible for the colours seen in a broad variety of flowers, fruits, vegetables and roots. ${ }^{22}$ From pink to red, violet and blue, anthocyanins present themselves as versatile compounds that can change their colour (by means of structural variations) depending on external stimuli such as $\mathrm{pH}$, temperature and light. In fact, they share in common the same chemical equilibrium network in acid to neutral medium (Figure 1). In the case of anthocyanins, flavylium cation $\left(\mathbf{A H}^{+}\right)$is the only species present in very acidic medium. Once the $\mathrm{pH}$ is raised two parallel reactions can take place: deprotonation of phenol groups in the flavylium structure to form the blue quinoidal base (A) and/or hydration to form a colorless hemiketal (B). Since hemiketal formation occurs from the hydration of the flavylium cation and not from the quinoidal base, these two reactions are competitive. Consequently, upon $\mathrm{pH}$ increase, $\mathbf{A}$ appears as a kinetic product, but since it is fairly unstable at equilibrium, it gradually disappears with time to form hemiketal through the flavylium cation. The hemiketal undergoes tautomerization which leads to the formation of the pale yellow cis-chalcone $(\mathbf{C c})$, and finally (in a longer timescale) cis-chalcone isomerizes and gives the trans-chalcone $(\mathbf{C t}){ }^{22}$

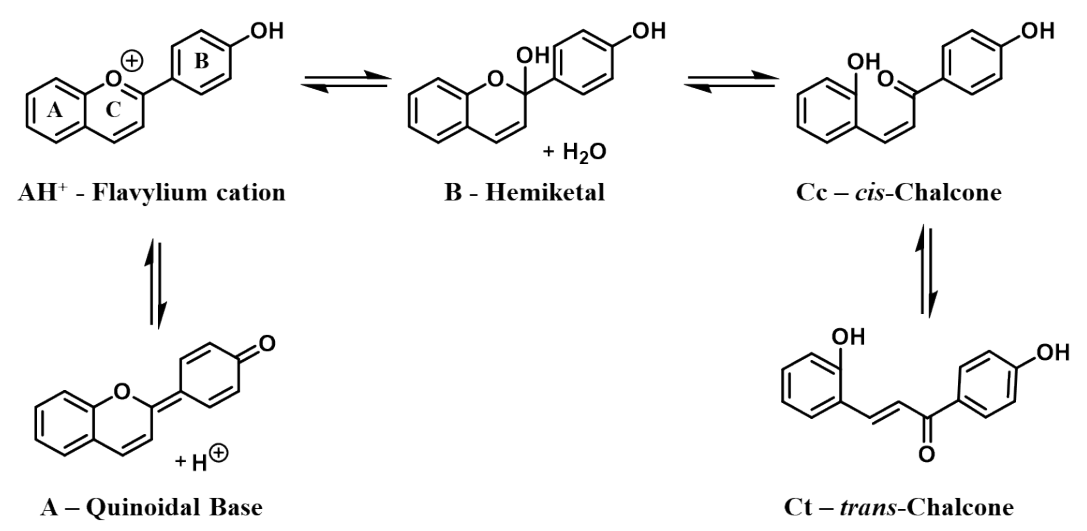

Figure 1 - Flavylium network of chemical reactions exemplified from 4'-hydroxyflavylium.

Anthocyanins are, as well, the main polyphenolic dyes found in young red wines, which can be transformed into more stable structures such as pyranoanthocyanins, during wine ageing and maturation. Pyranoanthocyanins display different chromatic hues with a wide range of colors from 
yellow to blue. Furthermore, pyranoanthocyanins have been shown to display higher color intensity and stability at a wider $\mathrm{pH}$ range comparatively to their anthocyanin precursors. ${ }^{23,24}$ In fact, while anthocyanins practically lose their red color between $\mathrm{pH} 1$ and 5, as a result of the formation of colorless hemiketals, pyranoanthocyanins practically do not change their color intensity. ${ }^{23,24}$ For these reasons, these dyes are interesting for a wide range of potential applications namely as food colorants, hair dyes, laser dyes, as well as photosensitizers for medical applications namely in photodynamic therapy and for energy applications such as DSSCs..$^{25,26}$

However, these natural occurring dyes develop through Nature's evolution process, optimizing and rearranging according to its needs. In fact, some natural flavylium derivatives, such as cyanidin, delphinidin and petunidin, can anchor efficiently to $\mathrm{TiO}_{2}$ through the catechol unit in the $\mathrm{B}$ ring, but do not have the donor-acceptor pattern optimized for electron transfer. So, for DSSC purposes, for example, it is possible to follow a bio-inspired strategy and with the adequate structural modifications prepare quasi-natural biomimetic compounds. With simple, non-toxic and environmentally safe synthetic procedures it is possible to design and prepare compounds with similar properties of natural occurring anthocyanins while tailoring desired energy levels, absorption properties and linker units. In fact, recently a yield of $2.2 \%$ was obtained with the compound 7-diethylamino-3',4'-dihydroxyflavylium (and upon device assembly optimization an efficiency of $3.0 \%$ was achieved, using the same compound). ${ }^{17,27}$ Anchoring to $\mathrm{TiO}_{2}$ is one of such traits that can be optimized and can greatly influence the overall cell efficiency. In flavylium derivatives, $\mathrm{TiO}_{2}$ anchoring is expected to happen through the quinoidal base form. ${ }^{17,27,28}$ But different linker units have different impacts on dye adsorption and electron injection.

In this work, a series of pyranoanthocyanin derivatives were designed, synthesized and applied as dye sensitizers in DSSCs, Figure 2. The spectral response and current vs. potential properties of photoanodes using these dyes were measured. A relation was established between dye structure and cell efficiency. Specifically, the influence of different linker units, carboxyl and catechol, was studied in terms of their influence in the various parameters related to DSSC efficiency. 

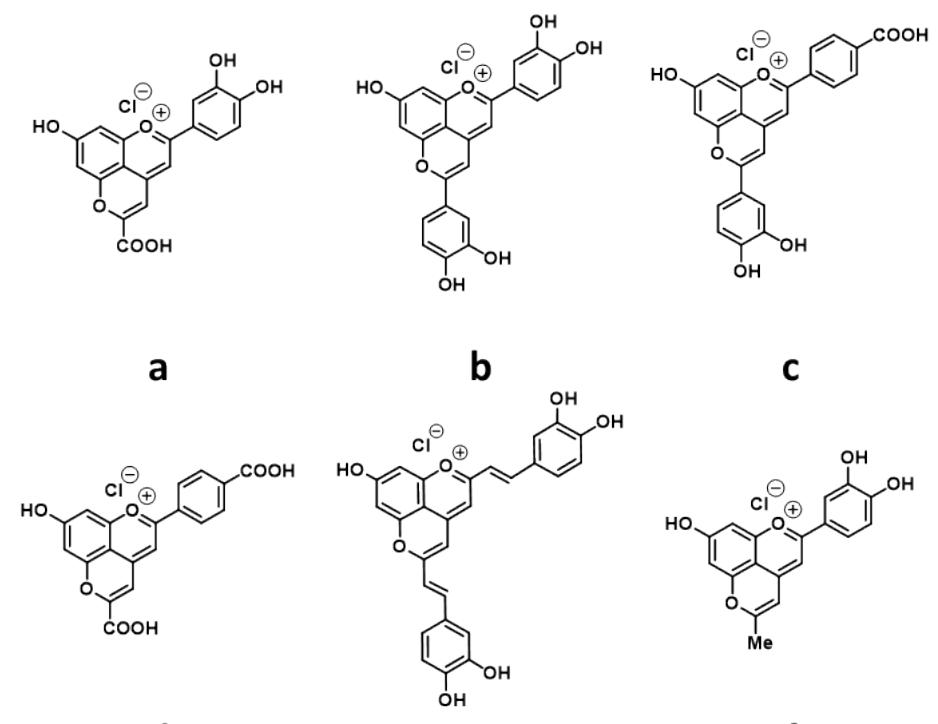

d

e

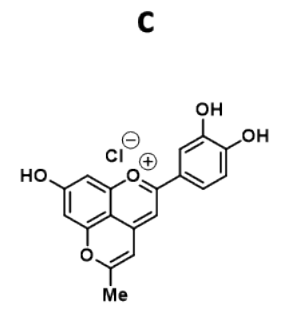

Figure 2 - Chemical structures of the six pyranoflavylium dyes studied in this work.

\section{Experimental}

\section{General information and instruments}

All solvents and chemicals employed for synthesis and for preparation of samples were of reagent or spectrophotometric grade and were used as received.

Synthesis - The syntheses of compounds $\mathbf{a}$ and $\mathbf{d}^{23}, \mathbf{b}$ and $\mathbf{f}^{24}$ and $\mathbf{e}^{29}$ were previously described.

Pyrano-4'-carboxy-7-hydroxyflavylium-10-catechol (c) Caffeic acid (1.6 mmol,10 eq.) was added to a solution of 4'-carboxy-5,7-dihydroxyflavylium $(0.132 \mathrm{mmol}, 50 \mathrm{mg})$ previously obtained, ${ }^{23}$ in a mixture of $\mathrm{H}_{2} \mathrm{O} / \mathrm{EtOH}(60: 40)(\mathrm{v} / \mathrm{v})(50 \mathrm{~mL})$ and $\mathrm{pH}$ was set to 3.5. The reaction mixture was left at $60{ }^{\circ} \mathrm{C}$ for 5 days. Then, the ethanol was evaporated, and the crude product was pre-purified in a Buchner funnel loaded with $\mathrm{C} 18$ silica gel and eluted with acidified aqueous solution containing $30-60 \%$ of $\mathrm{MeOH}$. The product was isolated by column chromatography using C18 silica gel with $50 \%$ of acidified $\mathrm{MeOH}$. A dark orange powder was obtained with $8 \%$ yield.

${ }^{1} \mathrm{H}$ NMR (600 MHz, DMSO-d 6 /TFA 9:1) $\delta 8.26(\mathrm{~d}, \mathrm{~J}=8.4 \mathrm{~Hz}, 2 \mathrm{H}, \mathrm{H} 2$ ' and H6'), 8.16 (d, J = 8.4 Hz, 2H, H3' and H5'), 7.82 (s, 1H, H3), 7.68 (dd, J = 8.5, 2.1 Hz, 1H, H6'), 7.63 (s, 1H, H9), 7.61 (d, J = 2.2 Hz, 1H, H2''), $7.25-7.21(\mathrm{~m}, 2 \mathrm{H}, \mathrm{H} 6$ and $\mathrm{H} 8), 7.01$ (d, J = 8.5 Hz, 1H, H5' '). ${ }^{13} \mathrm{C}$ NMR (151 MHz, DMSO-d 6 /TFA 9:1) $\delta 168.77$ (C10), 167.62 (C7), 166.83 (4'-COOH), 164.58 (C2), 153.80 (C5 or C8a or C4',), 153.70 (C5 or C8a or C4' '), 153.44 (C5 or C8a or C4'”), 151.04 (C4), 146.91 (C3''), 135.25 (C4'), 133.92 (C1'), 130.57 (C3' and C5'), 127.75 (C2' and C6'), 122.41 (C6'), 120.82 (C1'’), 117.08 (C5'), 114.90 (C2'), 108.17 (C4a), 104.12 (C3), 101.97 (C9), 100.99 (C6 or C8), 100.88 (C6 or C8). LC-DAD/ESI-MS: [M] $]^{+} m / z 415$, calculated for $\mathrm{C}_{24} \mathrm{H}_{15} \mathrm{O}_{7}{ }^{+}$: 415.1 . 
Physico-chemical characterization of the compounds - Optical measurements: The UV-Vis absorption spectra of the solutions and the dyes adsorbed to $\mathrm{TiO}_{2}$ in transmittance mode were recorded by a Varian Cary 5000. All the spectra were collected at room temperature.

Electrochemical measurements: Cyclic voltammetry (CV) and differential pulse voltammetry (DPV) measurements were performed on a $\mu$ Autolab Type III potentiostat/galvanostat, controlled with GPES software version 4.9 (Eco-Chemie), using a cylindrical $5 \mathrm{~mL}$ three-electrode cell. A Pt wire was used as counter-electrode. To perform the measurements on the $\mathrm{I}^{-} / \mathrm{I}^{-}{ }^{-}$system, a glassy carbon electrode (MF-2013, $\mathrm{f}=1.6 \mathrm{~mm}$, BAS inc.) was used as the working electrode. Prior to use, the working electrode was polished in aqueous suspensions of 1.0 and $0.3 \mathrm{~mm}$ alumina (Beuhler) over 2-7/" micro-cloth (Beuhler) polishing pads, then rinsed with water and ethanol. This cleaning procedure was always applied before any electrochemical measurements. The electrolyte composition was $0.1 \mathrm{M}$ tetrabutylammonium tetrafluoroborate, $10 \mathrm{mM}$ LiI in acetonitrile:valeronitrile $(85: 15, \% \mathrm{v} / \mathrm{v})$. To perform the measurements on the dye-coated $\mathrm{TiO}_{2}$ films, the films themselves were used as working electrode. A fresh sample was used for each scan to avoid uncertainty due to degradation between scans. The electrolyte composition was $0.1 \mathrm{M}$ tetrabutylammonium tetrafluoroborate in acetonitrile:valeronitrile $(85: 15, \% \mathrm{v} / \mathrm{v})$. All potentials refer to an SCE (Saturated $\mathrm{KCl}$ ) reference electrode (Metrohm). CV measurements were performed between 0 and $+1 \mathrm{~V}$, with a scan rate of $50 \mathrm{mV} / \mathrm{s}$. DPV measurements were performed between 0 and $+1 \mathrm{~V}$, using scan rate 5 and $10 \mathrm{mV} / \mathrm{s}$ and a pulse amplitude of $50 \mathrm{mV}$. The samples in the electrochemical cell were de-aerated by purging with nitrogen for 10 minutes prior to, and during, the electrochemical measurements.

Photoelectrochemical Measurements - Current-Voltage curves were recorded by a digital Keithley SourceMeter multimeter (PVIV-1A) connected to a PC. Simulated sunlight irradiation was provided by an Oriel solar simulator (Model LCS-100 Small Area Sol1A, 300 W Xe Arc lamp equipped with AM 1.5 filter, $100 \mathrm{~mW} / \mathrm{cm}^{2}$ ).

The thickness of the oxide film deposited on the photoanodes and the oxide film used for UV-Vis absorption experiments were measured using an Alpha-Step D600 Stylus Profiler (KLA-Tencor).

\section{DSSCs fabrication and photovoltaic characterization}

The conductive FTO-glass (TEC7, Greatcell Solar) used for the preparation of the transparent electrodes was first cleaned with detergent and then washed with water and ethanol. To prepare the anodes, the conductive glass plates were immersed in a $\mathrm{TiCl}_{4} /$ water solution $(40 \mathrm{mM})$ at $70{ }^{\circ} \mathrm{C}$ for $30 \mathrm{~min}$, washed with water and ethanol and sintered at $500^{\circ} \mathrm{C}$ for 30 minutes. The $\mathrm{TiO}_{2}$ nanocrystalline layers were deposited on the FTO plates by screen-printing the transparent titania paste (18NR-T, Greatcell Solar) using a frame with polyester fibres having 43.80 mesh per $\mathrm{cm}^{2}$. This procedure, involving two steps (coating and drying at $125^{\circ} \mathrm{C}$ ), was repeated two times. The $\mathrm{TiO}_{2}$ coated plates were gradually heated up to $325^{\circ} \mathrm{C}$, then the temperature was increased to 375 ${ }^{\circ} \mathrm{C}$ in 5 minutes, and afterwards to $500{ }^{\circ} \mathrm{C}$. The plates were sintered at this temperature for $15 \mathrm{~min}$, and finally cooled down to room temperature. Afterwards the $\mathrm{TiO}_{2}$ film was treated with the same $\mathrm{TiCl}_{4} /$ water solution $(40 \mathrm{mM})$, following the procedure previously described. A coating of reflector titania paste (WER2-O, Greatcell Solar) was deposited by screen-printing and sintered at $500{ }^{\circ} \mathrm{C}$. Each anode was cut into rectangular pieces (area: $2 \mathrm{~cm} \times 1.5 \mathrm{~cm}$ ) having a spot area of $0.196 \mathrm{~cm}^{2}$ 
with a thickness of $15 \mu \mathrm{m}$. The titanium oxide film employed for UV-Vis absorption experiments was prepared by doctor blade: two edges of the glass plate were covered with stripes of an adhesive tape (3 M Magic) in order to obtain a transparent ultrathin $\mathrm{TiO}_{2}$ film with an estimated thickness of about $6 \mu \mathrm{m}$. Dye solutions of the pyranoflavylium salts $(0.5 \mathrm{mM})$ were prepared in ethanol. The photoanodes were prepared by soaking the screen-printed glasses overnight $(\sim 17 \mathrm{~h})$ in the different dye solutions, at room temperature in the dark. The excess dye was removed by rinsing the photoanodes with the same solvent as that employed in the dye solution.

Each counter-electrode consisted of an FTO-glass plate (area: $2 \mathrm{~cm} \times 2 \mathrm{~cm}$ ) in which a hole $(1.5$ $\mathrm{mm}$ diameter) was drilled. The perforated substrates were washed and cleaned with water and ethanol in order to remove any residual glass powder and organic contaminants. The Pt transparent catalyst (PT1, Grealcell Solar) was deposited on the conductive face of the FTO-glass by doctor blade: one edge of the glass plate was covered with a stripe of an adhesive tape (3 M Magic) both to control the thickness of the film and to mask an electric contact strip. The Pt paste was spread uniformly on the substrate by sliding a glass rod along the tape spacer. The adhesive tape stripe was removed, and the glasses heated at $550{ }^{\circ} \mathrm{C}$ for $30 \mathrm{~min}$. The photoanode and the Pt counter-electrode were assembled into a sandwich type arrangement and sealed (using a thermopress) with a hot melt gasket made of Surlyn ionomer (Meltonix 1170-25, Solaronix SA).

The electrolyte was prepared by dissolving the redox couple, $\mathrm{I}^{-} / \mathrm{I}_{2}\left(0.8 \mathrm{M} \mathrm{LiI}\right.$ and $\left.0.05 \mathrm{M} \mathrm{I}_{2}\right)$, in acetonitrile/valeronitrile $(85: 15, \% \mathrm{v} / \mathrm{v})$ mixture. The electrolyte was introduced in to the cell via backfilling under vacuum through a hole in the back of the cathode. Finally, the hole was sealed with adhesive tape.

For each compound, three cells were assembled under the same conditions, and the efficiencies were measured 10 times for each one resulting in 30 measurements per compound, in order to calculate average and standard deviation values.

\section{Results and Discussion}

\section{UV-Vis absorption}

Dye sensitization plays a crucial role in DSSCs. A dye for DSSC should ideally absorb solar radiation strongly with absorption bands in the visible and NIR region, preferably covering a wide range of wavelengths. The absorption spectra of compounds $\mathbf{a}-\mathbf{f}$ in ethanol $(0.05 \mathrm{mM})$ are shown in Figure 3. Compound $\mathbf{d}$ has the most blue-shifted absorption maximum (458 nm) followed by compounds f $(476 \mathrm{~nm}), \mathbf{a}(495 \mathrm{~nm}), \mathbf{b}(503 \mathrm{~nm})$ and $\mathbf{c}(504 \mathrm{~nm})$. Compound exhibits an absorption maximum at lower energies $(582 \mathrm{~nm})$ when compared with the other compounds, reflecting the effect of extending the conjugation through a styryl unit to the catechol groups. In addition, since it has a broader band, absorbing a wider range of visible frequencies, it gives rise to a darker colored solution and film (see insets in Figures 3 and 4, respectively). Since these solutions were prepared in ethanol, with no addition of acid, some of these absorption maxima may already have a contribution from the presence of quinoidal base species. Upon adsorption onto $\mathrm{TiO}_{2}$ (Figure 4) all compounds show red-shifted absorption maxima (between 8 and $27 \mathrm{~nm}$ for compounds e and a, respectively), maintaining however the same qualitative behaviour. This is an indication that $\mathrm{TiO}_{2}$ adsorption involves coordination to the Ti(IV) via a quinoidal base formed upon deprotonation of the flavylium cation. The interaction of flavylium cations with some metal ions such as aluminium, 
iron and titanium, is known to involve deprotonation and formation of metal complexes with the quinoidal bases, displacing the flavylium-quinoidal equilibrium toward the complexing quinoidal form. ${ }^{12,30,31}$ Five of the six studied compounds (a, b, $\left., \mathbf{e}, \mathbf{f}\right)$ exhibited strong absorptions in the Visible region and this characteristic makes them potential candidates for light harvesting in DSSCs.

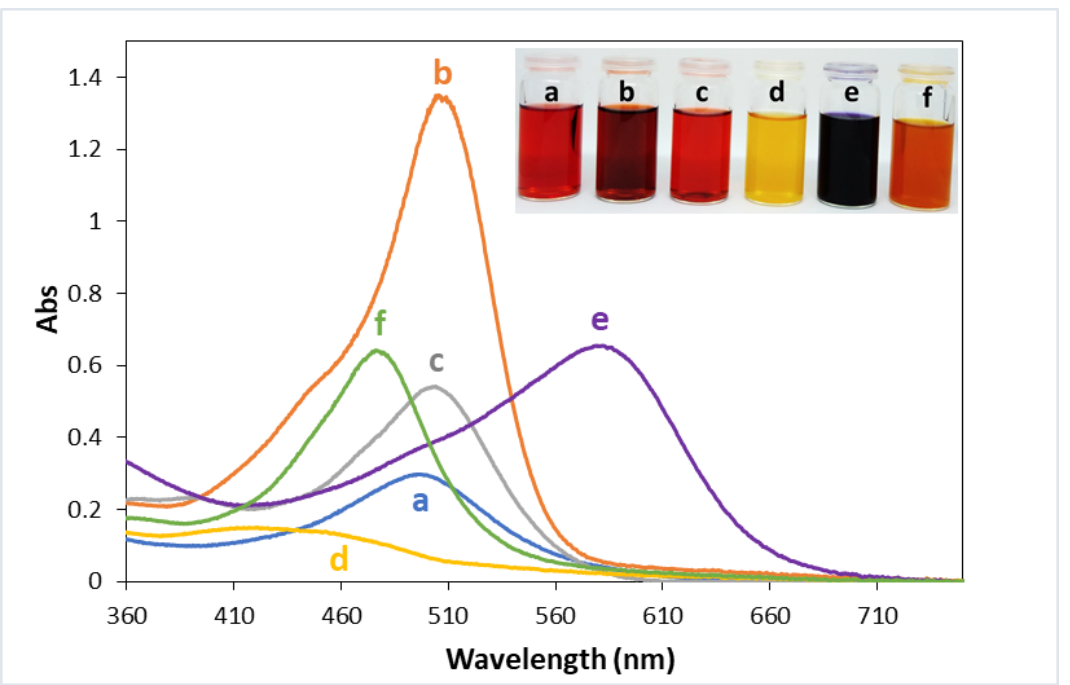

Figure 3 - UV-Vis absorption spectra of compounds a - f $0.05 \mathrm{mM}$ in ethanol. Inset: solutions of the compounds.

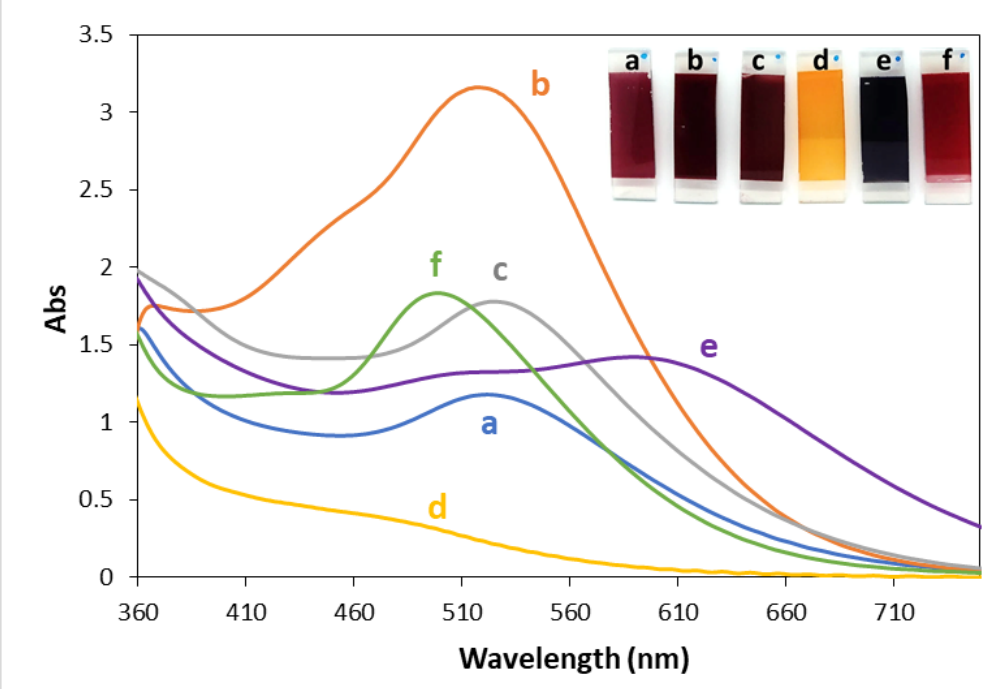

Figure 4 - UV-Vis absorption spectra of compounds a - f $0.5 \mathrm{mM}$ in ethanol, adsorbed on a thin (ca. $6 \mu \mathrm{m})$ $\mathrm{TiO}_{2}$ film on FTO glass. Inset: picture of the films.

\section{Electrochemical properties}


Cyclic and Differential Pulse Voltammetry were used to characterize the compounds electrochemically (see Supplementary Information for full CV and DPV voltammograms). The anodic oxidation peaks obtained from DPV data are presented in Table 1. The minimum value of $E_{p a}=0.332 \mathrm{~V}$ was obtained for compound e containing two styryl moieties and two catechol groups, one in each styryl unit. Compound $\mathbf{b}$ comes next with two catechol units and $\mathrm{E}_{\mathrm{pa}}=0.366 \mathrm{~V}$. Compounds a, $\mathbf{c}$ and $\mathbf{f}$, containing only one catechol group and carboxylic acid or methyl groups, are characterized by higher $E_{\mathrm{pa}}$ values. These results are a consequence of the electrondonor/acceptor character of the substituents on the pyranoflavylium core. Compounds possessing catechol units, which are electron-donating substituents, and extended conjugation (styryl moieties) are easier to oxidize, resulting in lower oxidation potentials. The presence of the methyl group, a mild electron-donor through hyperconjugation, or of electron-withdrawing carboxylic acid groups contribute to increase the oxidation potential.

Table 1 - First anodic oxidation potentials of dyes a - $\mathbf{f}$ adsorbed to $\mathrm{TiO}_{2}$, obtained through Differential Pulse Voltammetry (E vs. SCE) in acetonitrile:valeronitrile $(85: 15, \% \mathrm{v} / \mathrm{v})$.

\begin{tabular}{cc}
\hline Dye & $\mathbf{E}_{\mathbf{p a}}(\mathbf{V})$ \\
\hline $\mathbf{a}$ & 0.527 \\
$\mathbf{b}$ & 0.366 \\
$\mathbf{c}$ & 0.645 \\
$\mathbf{d}$ & $\sim 0.6^{\mathrm{a}}$ \\
$\mathbf{e}$ & 0.332 \\
$\mathbf{f}$ & 0.508 \\
\hline
\end{tabular}

${ }^{\text {a }}$ The low intensity of the signal prevents a better definition of $E_{\mathrm{pa}}$.

An important thermodynamic requirement for dyes to be used in DSSC technology is that electron transfer from the excited state of the dye to $\mathrm{TiO}_{2}$ must be faster than the decay to the ground state. The LUMO of the dye must then be sufficiently high in energy for efficient charge injection into the $\mathrm{TiO}_{2}$ conduction band $(-4.24 \mathrm{eV})^{2}$. Also, the HOMO level of the sensitizer must be sufficiently low in energy for efficient regeneration of the oxidized dye by the redox couple. ${ }^{1,2,17}$ To experimentally determine the HOMO and LUMO energy levels of the dyes, the first oxidation and reduction potentials obtained from CV experiments may, respectively, be used. Alternatively, the LUMO energy can be obtained by adding the optical absorption energy to the HOMO value. ${ }^{32}$ In here, we considered the first anodic oxidation peak obtained from DPV performed on the dyes adsorbed on $\mathrm{TiO}_{2}$, hence determining the $\mathrm{HOMO}$ of the dye- $\mathrm{TiO}_{2}$ complex $\left(\mathrm{HOMO}_{\text {dye } @ \mathrm{TiO}}\right)$ (Eq. 1). Addition of the optical absorption energy obtained from the spectra in Figure 4 allowed to obtain the LUMO energy for the dye- $\mathrm{TiO}_{2}$ complex $\left(\mathrm{LUMO}_{\text {dye } @ \mathrm{TiO} 2}\right)$ (Eq. 2). These results are presented in Table 2.

$$
\begin{aligned}
& \mathrm{E}\left(\mathrm{HOMO}_{\text {dye } @ \mathrm{TiO} 2}\right)=-\left(\mathrm{E}_{\mathrm{pa}}(\text { vs. SCE })+4.44\right) \mathrm{eV} \\
& \mathrm{E}\left(\mathrm{LUMO}_{\text {dye } @ \mathrm{TiO} 2}\right)=\mathrm{E}\left(\mathrm{HOMO}_{\text {dye } @ \mathrm{TiO} 2}\right)+\mathrm{E}_{\text {absorption edge }} \mathrm{eV}
\end{aligned}
$$


Table 2 - HOMO and LUMO energy levels of the dye- $\mathrm{TiO}_{2}$ complex calculated from optical and electrochemical data.

\begin{tabular}{cccccc}
\hline Dye & $\begin{array}{c}\text { Absorption } \\
\text { edge }(\mathbf{n m})\end{array}$ & $\begin{array}{c}\text { Energy } \\
(\mathbf{e V})\end{array}$ & $\begin{array}{c}\text { HOMO }_{\text {dye } @ \text { TiO2 }} \text { vs. } \\
\text { SCE (V) }\end{array}$ & $\begin{array}{c}\text { HOMO }_{\text {dye } @ \text { TiO2 }} \text { vs. } \\
\text { Vacuum (eV) }\end{array}$ & $\begin{array}{c}\text { LUMO }_{\text {dye } @ \text { TiO2 }} \text { vs. } \\
\text { Vacuum (eV) }\end{array}$ \\
\hline $\mathbf{a}$ & 522 & 2.375 & 0.527 & -4.967 & -2.592 \\
$\mathbf{b}$ & 518 & 2.394 & 0.366 & -4.806 & -2.412 \\
$\mathbf{c}$ & 525 & 2.361 & 0.645 & -5.085 & -2.724 \\
$\mathbf{d}$ & 470 & 2.638 & - & - & - \\
$\mathbf{e}$ & 590 & 2.101 & 0.332 & -4.772 & -2.671 \\
$\mathbf{f}$ & 499 & 2.485 & 0.508 & -4.948 & -2.463 \\
\hline
\end{tabular}

$\mathrm{E}\left(\mathrm{HOMO}_{\mathrm{dye} @ \mathrm{TiO} 2}\right)=-\left(\mathrm{E}_{\mathrm{pa}}(v s . \mathrm{SCE})+4.44\right) \mathrm{eV}$

(Eq. 1)

$\mathrm{E}\left(\mathrm{LUMO}_{\text {dye } @ \mathrm{TiO} 2}\right)=\mathrm{E}\left(\mathrm{HOMO}_{\text {dye } @ \mathrm{TiO} 2}\right)+\mathrm{E}_{\text {absorption edge }} \mathrm{eV}$

(Eq. 2)

Table 2Since we are determining the HOMO and LUMO energies of the dye- $\mathrm{TiO}_{2}$ complex, we will consider electron injection into the Fermi level potential of the FTO $(-4.4 \mathrm{eV})^{32}$, instead of the $\mathrm{TiO}_{2}$ conduction band $(-4.24 \mathrm{eV})$, when evaluating electron injection ability. ${ }^{32} \mathrm{~A}$ schematic representation of the energy levels of the dyes adsorbed onto $\mathrm{TiO}_{2}$ versus the Fermi level potential of the FTO $(-4.4 \mathrm{eV})$ and the calculated redox potential of the redox couple $\mathrm{I}^{-} / \mathrm{I}_{3}{ }^{-}(-4.718 \mathrm{eV})$ is represented in Figure 5. All the studied pyranoflavylium dye- $\mathrm{TiO}_{2}$ complexes should be able to inject electrons into the FTO band, given that for every case the difference between the LUMO and the potential of the FTO is $\sim 2 \mathrm{eV}$. In the case of the HOMO level, it is possible to identify two distinct groups. Although all the pyranoflavylium compounds possess a HOMO energy level below the potential of $\mathrm{I}^{-} / \mathrm{I}_{3}^{-}$, thus being able to be reduced by the electrolyte, for dyes $\mathbf{b}$ and $\mathbf{e}$ this difference is quite small ( 0.088 and $0.054 \mathrm{eV}$, respectively). This fact can result in inefficient regeneration of the compounds by the electrolyte, affecting the performance of the cell. In the case of dyes a, $\mathbf{c}$ and $\mathbf{f}$, this difference is higher than $0.2 \mathrm{eV}$, rendering these compounds easy to regenerate by the electrolyte, thus resulting in well-functioning devices. 


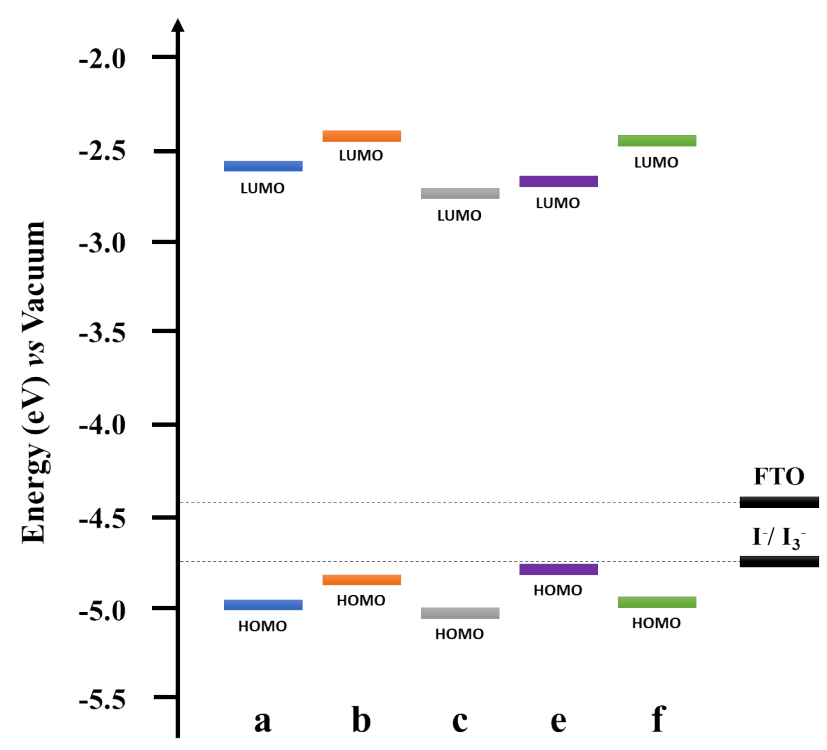

Figure 5 - Schematic representation of the energy level diagram $\left(\mathrm{HOMO}_{\text {dye } @ \mathrm{TiO} 2}\right.$ and $\left.\mathrm{LUMO}_{\text {dye } @ \mathrm{TiO} 2}\right)$ of the pyranoflavylium dyes adsorbed onto the $\mathrm{TiO}_{2}$ film $v$ s. the $\mathrm{FTO}$ and $\mathrm{I}^{-} / \mathrm{I}_{3}^{-}$redox potentials.

\section{DSSCs photovoltaic performance}

The photocurrent-voltage plots for DSSCs assembled with pyranoflavylium dyes $\mathbf{a}-\mathbf{f}$ are shown in Figure 6. Analysis of these data allowed to determine the short circuit current density $\left(\mathrm{J}_{\mathrm{SC}}\right)$, open circuit voltage $\left(\mathrm{V}_{\mathrm{OC}}\right)$, fill factor $(\mathrm{FF})$ and overall conversion efficiency $(\eta)$, summarized in Table 3.

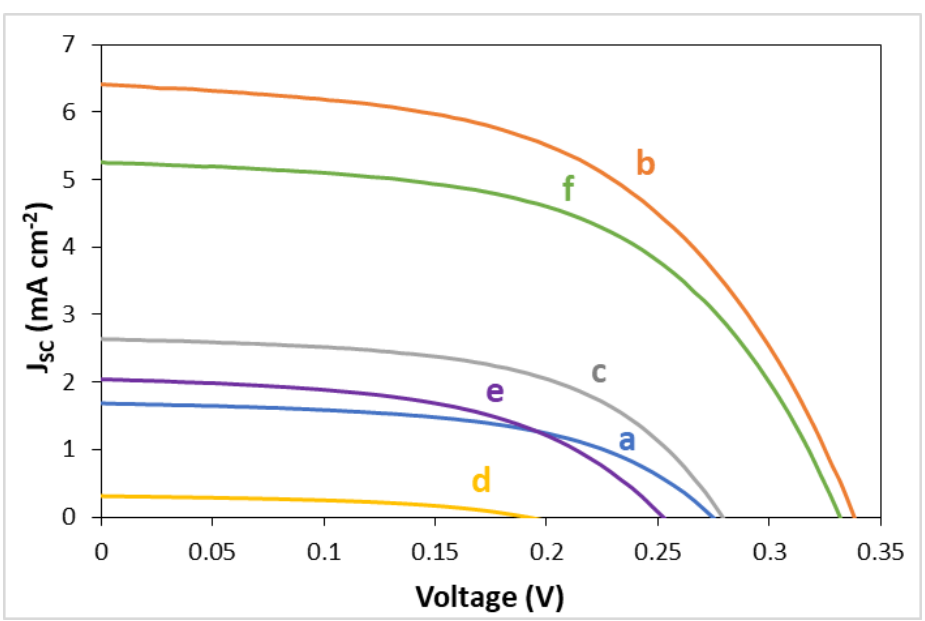

Figure 6 - J-V curves of DSSCs based on dyes a - f measured under AM 1.5 solar light $\left(100 \mathrm{~mW} \mathrm{~cm} \mathrm{~cm}^{-2}\right)$, using $0.8 \mathrm{M} \mathrm{LiI}$ and $0.05 \mathrm{M} \mathrm{I}_{2}$ in acetonitrile:valeronitrile $(85: 15, \% \mathrm{v} / \mathrm{v})$ as electrolyte. 
Table 3 - Photovoltaic performance parameters of DSSCs based on pyranoflavylium dyes a - f, under 100 $\mathrm{mW} \mathrm{cm}{ }^{-2}$ simulated AM 1.5 illumination. $\lambda_{\max } / \mathbf{A}_{\max }$ refers to the absorption maxima and respective absorbance measured in transmission mode for each dye upon adsorption over $\mathrm{TiO}_{2}$. The results presented are for the best performing cell.

\begin{tabular}{cccccccc}
\hline Dye & $\boldsymbol{\lambda}_{\max } / \mathbf{A}_{\mathbf{m a x}}$ & $\mathbf{J}_{\mathbf{S C}}\left(\mathbf{m A ~ \mathbf { ~ m } ^ { - 2 } )}\right.$ & $\mathbf{V}_{\mathbf{O C}}(\mathbf{m V})$ & $\mathrm{FF}$ & $\mathbf{J}_{\mathbf{m a x}}\left(\mathbf{m A ~ \mathbf { c m } ^ { - 2 }}\right)$ & $\mathbf{V}_{\max }(\mathbf{m V})$ & $\boldsymbol{\eta}(\mathbf{\%})$ \\
\hline $\mathbf{a}$ & $522 / 1.18$ & 1.68 & 274 & 0.54 & 1.28 & 194 & 0.25 \\
$\mathbf{b}$ & $518 / 3.16$ & 6.43 & 338 & 0.53 & 5.02 & 229 & 1.15 \\
$\mathbf{c}$ & $525 / 1.78$ & 2.63 & 279 & 0.56 & 2.06 & 199 & 0.41 \\
$\mathbf{d}$ & $483 / 0.36$ & 0.31 & 191 & 0.46 & 0.21 & 129 & 0.03 \\
$\mathbf{e}$ & $590 / 1.42$ & 2.03 & 252 & 0.51 & 1.53 & 172 & 0.26 \\
$\mathbf{f}$ & $499 / 1.83$ & 5.26 & 332 & 0.56 & 4.16 & 233 & 0.97 \\
\hline
\end{tabular}

Lithium is known to act as a $\mathrm{TiO}_{2}$ Fermi level stabilizer, thus moving $\mathrm{TiO}_{2}$ conduction band towards more positive potentials, favouring the photocurrent over the potential. ${ }^{33}$ Since the photovoltage generated by the cell under illumination corresponds to the difference between the Fermi level of the electron in the semiconductor and the redox potential of the electrolyte, ${ }^{3}$ the electrolyte composition is determinant to the $\mathrm{V}_{\mathrm{OC}}$ values obtained.

Nevertheless, the structural features of the compounds also affect significantly the values obtained. The most relevant observation is that the presence of acidic groups such as $-\mathrm{COOH}$, contributes to the decrease of $\mathrm{V}_{\mathrm{OC}}$, as shown in the literature for $\mathrm{N} 3 v s$. N719. ${ }^{34}$ This effect is notorious on the $\mathrm{V}_{\mathrm{OC}}$ of $\mathbf{a}(274 \mathrm{mV})$ and $\mathbf{c}(279 \mathrm{mV})$, possessing one carboxylic group each, when compared with d (191 $\mathrm{mV})$ possessing two carboxylic groups or $\mathbf{b}(338 \mathrm{mV})$ and $\mathbf{f}(332 \mathrm{mV})$ which have no carboxylic units.

Compound e, containing two styryl groups, does not follow this pattern. In this case, a decrease in $\mathrm{V}_{\mathrm{OC}}$ from 338 to $252 \mathrm{mV}$ with respect to the $\mathbf{b}$ analogue is observed due to a change in the direction of dipolar moment, as previously shown for ruthenium derivatives. ${ }^{35}$

On the other hand, for a comparison of the overall performances, we have to take into consideration that $\mathrm{J}_{\mathrm{SC}}$ is strongly affected by the amount of absorbed light, which is significantly different among the several dyes. A plot of the absorbance at the absorption maximum for each dye (Figure 4) against the short circuit current, yields a straight line (Figure 7), which means that the absorption corrected $\mathrm{J}_{\mathrm{SC}}$ values would be comparable for the series. Dyes $\mathbf{b}$ and $\mathbf{f}$, possessing only hydroxyl groups, present $\mathrm{J}_{\mathrm{SC}}$ values slightly higher than the linear correlation defined by the other dyes. This suggests that carboxylates (a, c, d) decrease electron injection and/or increase recombination, conveying them as poorer anchoring groups in these family of dyes. 
Figure 7 - Relation between the absorbance at $\lambda_{\max }$ for $\mathbf{a}-\mathbf{f}$ dye- $\mathrm{TiO}_{2}$ complexes and the respective $\mathrm{J}_{\mathrm{SC}}$ measured for the best efficiency performance. The error bars correspond to the $\mathrm{J}_{\mathrm{SC}}$ results obtained for 3 DSSCs assembled for each compound, measured 10 times each.

Despite the evident difference in absorbance, with that of a being almost 3-fold higher than that for d (1.18 vs. 0.36 , respectively, as measured by the absorbance at $\left.\lambda_{\max }\right)$ this difference by itself is not sufficient to account for the $\sim 9$-fold decrease in overall DSSC efficiency $(0.25 \% v s .0 .03 \%$, respectively). This difference is however mostly justified by the $\sim 6$-fold decrease in $\mathrm{J}_{\mathrm{SC}}(1.68$ $v s .0 .31$, for a and $\mathbf{d}$ respectively). So, the photocurrent must also reflect, additionally to the higher amount of absorbed light, a better electron injection on the $\mathrm{TiO}_{2}$ conduction band for compound $\mathbf{a}$. Compound $\mathbf{b}$ is the best performing dye with an efficiency of $1.15 \%$, under the present (nonoptimized) conditions, and the highest $\mathrm{V}_{\mathrm{OC}}$ and $\mathrm{J}_{\mathrm{SC}}, 338 \mathrm{mV}$ and $6.43 \mathrm{~mA} . \mathrm{cm}^{-2}$, respectively. This is also the compound with the highest absorbance at $\lambda_{\max }$ (3.16) and the highest LUMO energy (-2.412 $\mathrm{eV})$. Compound $\mathbf{b}$ not only is the dye with the highest absorption, but also the compound with the better adjusted LUMO for improved electron injection into the $\mathrm{TiO}_{2}$ conduction band. Comparing these results with compound e (its styryl catechol analogue) we see for the latter an overall worse performance. Despite of the broader and red-shifted absorption band, compound $\mathbf{e}$ has lower absorbance (1.42), which corresponds to a lower light absorption under the same conditions, with direct impact in $\mathrm{J}_{\mathrm{SC}}\left(2.03 \mathrm{~mA} \cdot \mathrm{cm}^{-2}\right)$. Additionally, a reduction of $\sim 100 \mathrm{mV}$ in $\mathrm{V}_{\mathrm{OC}}$ further reduces the performance of dye e. This difference can as well be attributed to the lower LUMO energy of this compound $(-2.671 \mathrm{eV})$, resulting in lower $\mathrm{J}_{\mathrm{SC}}$. This can be due to the presence of cis- and transisomers in the styryl units anchored to $\mathrm{TiO}_{2}$. Probably, for different isomers, molecular orbitals may not always be optimized for electron charge transfer resulting in less effective electron injection.

Compounds $\mathbf{c}$ and $\mathbf{f}$ display an interesting "couple" since despite the almost insignificant difference in absorbance (1.78 and 1.83, respectively), the $\mathrm{J}_{\mathrm{SC}}$ measured (Figure 7 ) and, consequently the efficiencies, are quite different. Compound $\mathbf{f}$ has twice the value of $\mathrm{J}_{\mathrm{SC}}\left(5.26\right.$ vs. $2.63 \mathrm{~mA} . \mathrm{cm}^{-2}$, respectively) resulting in twice the efficiency $(0.97 \% v s .0 .41 \%$, respectively). This can be due to the significant difference in LUMO energies between the compounds, with that of compound $\mathbf{f}$ being higher than that of compound $\mathbf{c}(-2.463$ vs. $-2.724 \mathrm{eV})$. Once again, the compound with the 
higher LUMO is the one with a better $\mathrm{J}_{\mathrm{SC}}$ performance due to the higher driving force for electron injection into the $\mathrm{TiO}_{2}$ conduction band. Once more, the main difference between $\mathbf{c}$ and $\mathbf{f}$ is the presence of a carboxylic group in $\mathbf{c}$ which is absent in $\mathbf{f}$. In fact, a closer inspection of Figure 7 shows that also b, which lacks a carboxylic group, yields a slightly higher photocurrent than expected from the linear correlation with absorption.

In summary, the overall performance of these compounds in DSSCs is clearly dominated by light aborption of the dyes. We can further correlate the resulting efficiency with the nature of the linker units and their electron-donor/acceptor character. In this class of dyes, carboxylic groups seem to have a deleterious effect in electron injection due to their electron withdrawing character. Moreover, this same characteristic reflects in lower $\mathrm{J}_{\mathrm{SC}}$ results and, consequently, in lower cell efficiencies.

\section{Conclusions}

Pyranoanthocyanins display great potential as photosensitizers in bio-inspired DSSCs. The best known efficiency reported so far using this family of compounds is $0.006 \%$ for cyanidin-3-Oglucoside-pyruvic acid adduct. ${ }^{36}$ In this work, for the first time, six pyranoflavylium salts were synthesized following a bio-mimetic approach, and successfully applied, as light harvesters in DSSCs. An overall efficiency of $1.15 \%$ was obtained for the best performing compound, 10catecholpyrano-5,7,3',4'-tetrahydroxyplavylium (b), with no further optimization. When considering naturally occurring dyes, betalains which contain carboxylates as anchoring groups consistently show higher efficiencies compared to anthocyanins. ${ }^{8,11,37,38}$ This led to the idea that carboxylic linkage was essential in order to have strong electronic coupling and rapid forward and reverse electron transfer reactions between the dye and the DSSC. ${ }^{8,11}$ In this work, where both anchoring groups are compared within closely related molecules with the same pyranoflavylium core, it became clear that the presence of catechol unit increases electron injection to the $\mathrm{TiO}_{2}$ semiconductor. The electron withdrawing carboxylic units showed, on the other hand, a deleterious effect in electron injection reflected in lower $\mathrm{J}_{\mathrm{SC}}$ and, consequently, in lower cell efficiencies. In summary, the overall performance of these compounds in DSSCs is clearly dominated by the nature of the linker units and their electron-donor/acceptor character.

\section{Acknowledgements}

This work was supported by the Associate Laboratory for Green Chemistry, LAQV-REQUIMTE which is financed by national funds from FCT/MCTES (UID/QUI/50006/2013) and co-financed by the ERDF under the PT2020 Partnership Agreement (POCI-01-0145-FEDER - 007265). FCT/MCTES is acknowledged for Project PTDC/QEQ-QFI/1971/2014, grants $\mathrm{PD} / \mathrm{BD} / 135087 / 2017$ (ALP), SFRH/BD/136556/2018 (VG) and, a research FCT contract (LC). 


\section{References}

1. O’Regan, B. \& Grätzel, M. A low-cost, high-efficiency solar cell based on dyesensitized colloidal TiO2 films. Nature 353, 737-740 (1991).

2. Grätzel, M. Photoelectrochemical cells. Nature 414, 338-344 (2001).

3. Grätzel, M. Solar energy conversion by dye-sensitized photovoltaic cells. Inorg. Chem. 44, 6841-6851 (2005).

4. Nazeeruddin, M. K., Liska, P., Moser, J., Vlachopoulos, N. \& Gratzel, M. Conversion of Light into Electricity with Trinuclear Ruthenium Complexes Adsorbed on Textured TiO2 Films. Helv. Chim. Acta 73, 1788-1803 (1990).

5. Wang, Q., Moser, J.-E. \& Grätzel, M. Electrochemical impedance spectroscopic analysis of dye-sensitized solar cells. J. Phys. Chem. B 109, 14945-14953 (2005).

6. Sharma, K., Sharma, V. \& Sharma, S. S. Dye-Sensitized Solar Cells : Fundamentals and Current Status. Nanoscale Res. Lett. 6, 381 (2018).

7. Calogero, G. et al. Natural dye senstizers for photoelectrochemical cells. Energy Environ. Sci. 2, 1162-1172 (2009).

8. Calogero, G., Bartolotta, A., Di Marco, G., Di Carlo, A. \& Bonaccorso, F. Vegetable-based dye-sensitized solar cells. Chem. Soc. Rev. 44, 3244-3294 (2015).

9. Kay, A. \& Graetzel, M. Artificial photosynthesis. 1. Photosensitization of titania solar cells with chlorophyll derivatives and related natural porphyrins. J. Phys. Chem. 97, 6272-6277 (1993).

10. Lu, J., Liu, S. \& Wang, M. Push-Pull Zinc Porphyrins as Light-Harvesters for Efficient Dye-Sensitized Solar Cells. Front. Chem. 6, 541 (2018).

11. Calogero, G. et al. Anthocyanins and betalains as light-harvesting pigments for dyesensitized solar cells. Sol. Energy 86, 1563-1575 (2012).

12. Cherepy, N. J., Smestad, G. P., Grätzel, M. \& Zhang, J. Z. Ultrafast Electron Injection: Implications for a Photoelectrochemical Cell Utilizing an Anthocyanin Dye-Sensitized TiO2 Nanocrystalline Electrode. J. Phys. Chem. B 101, 9342-9351 (1997).

13. Wali, Q., Elumalai, N. K., Iqbal, Y., Uddin, A. \& Jose, R. Tandem perovskite solar cells. Renew. Sustain. Energy Rev. 84, 89-110 (2018).

14. Kalaiselvi, C. R., Muthukumarasamy, N., Velauthapillai, D., Kang, M. \& Senthil, T. $\mathrm{S}$. Importance of halide perovskites for next generation solar cells - A review. Mater. Lett. 219, 198-200 (2018).

15. Ng, C. H., Lim, H. N., Hayase, S., Zainal, Z. \& Huang, N. M. Photovoltaic performances of mono- and mixed-halide structures for perovskite solar cell: A review. Renew. Sustain. Energy Rev. 90, 248-274 (2018). 
16. Grätzel, M. Recent Advances in Sensitized Mesoscopic Solar Cells. Acc. Chem. Res. 42, 1788-1798 (2009).

17. Calogero, G. et al. Synthetic analogues of anthocyanins as sensitizers for dyesensitized solar cells. Photochem. Photobiol. Sci. 12, 883-94 (2013).

18. Hug, H., Bader, M., Mair, P. \& Glatzel, T. Biophotovoltaics: Natural pigments in dye-sensitized solar cells. Appl. Energy 115, 216-225 (2014).

19. Calogero, G. \& Marco, G. Di. Red Sicilian orange and purple eggplant fruits as natural sensitizers for dye-sensitized solar cells. Sol. Energy Mater. Sol. Cells 92, 1341-1346 (2008).

20. Mohiuddin, O., Obaidullah, M. \& Sabah, C. Improvement in dye sensitized solar cells from past to present. Opt. Quantum Electron. 50, 377 (2018).

21. Tennakone, K., Kumarasinghe, A. R., Kumara, G. R. R. A., Wijayantha, K. G. U. \& Sirimanne, P. M. Nanoporous TiO2 photoanode sensitized with the flower pigment cyanidin. J. Photochem. Photobiol. A Chem. 108, 193-195 (1997).

22. Pina, F., Melo, M. J., Laia, C. A. T., Parola, A. J. \& Lima, J. C. Chemistry and applications of flavylium compounds: a handful of colours. Chem. Soc. Rev. 41, 869-908 (2012).

23. Sousa, J. L. C. et al. Synthesis and equilibrium multistate of new pyrano-3deoxyanthocyanin-type pigments in aqueous solutions. Tetrahedron 73, 6021-6030 (2017).

24. Cruz, L., Sousa, J. L. C., Marinho, A., Mateus, N. \& de Freitas, V. Synthesis and structural characterization of novel pyranoluteolinidin dyes. Tetrahedron Lett. 58, 159-162 (2017).

25. Roque, A. et al. Photochromic properties of 3-methyl-substituted flavylium salts. European J. Org. Chem. 2699-2709 (2002).

26. Czerney, P., Graneß, G., Birckner, E., Vollmer, F. \& Rettig, W. Molecular engineering of cyanine-type fluorescent and laser dyes. J. Photochem. Photobiol. A Chem. 89, 31-36 (1995).

27. Calogero, G. et al. Electronic and charge transfer properties of bio-inspired flavylium ions for applications in TiO2-based dye-sensitized solar cells. Photochem. Photobiol. Sci. 16, 1400-1414 (2017).

28. Cherepy, N. J., Smestad, G. P., Grätzel, M. \& Zhang, J. Z. Ultrafast Electron Injection: Implications for a Photoelectrochemical Cell Utilizing an Anthocyanin Dye-Sensitized TiO2 Nanocrystalline Electrode. J. Phys. Chem. B 101, 9342-9351 (1997).

29. Gomes, V., Mateus, N., de Freitas, V. \& Cruz, L. Synthesis and Structural Characterization of a Novel Symmetrical 2,10-Bis-Styryl-1-Benzopyrylium Dye. 
Synlett 29, 1390-1394 (2018).

30. Goto, T. \& Kondo, T. Structure and Molecular Stacking of Anthocyanins - Flower Color Variation. Angew. Chemie - Int. Ed. Engl. 30, 17-33 (1991).

31. Bayer, E., Egeter, H., Fink, A., Nether, K. \& Wegmann, K. Complex Formation and Flower Colors. Angew. Chemie Int. Ed. English 5, 791-798 (1966).

32. Kavitha, S., Praveena, K. \& Lakshmi, M. A new method to evaluate the feasibility of a dye in DSSC application. Int. J. Energy Res. 41, 2173-2183 (2017).

33. Jennings, J. R. \& Wang, Q. Influence of Lithium Ion Concentration on Electron Injection, Transport, and Recombination in Dye-Sensitized Solar Cells. J. Phys. Chem. C 114, 1715-1724 (2010).

34. Nazeeruddin, M. K., Humphry-Baker, R., Liska, P. \& Grätzel, M. Investigation of Sensitizer Adsorption and the Influence of Protons on Current and Voltage of a DyeSensitized Nanocrystalline TiO2 Solar Cell. J. Phys. Chem. B 107, 8981-8987 (2003).

35. Moehl, T. et al. High Open-Circuit Voltages: Evidence for a Sensitizer-Induced $\mathrm{TiO} 2$ Conduction Band Shift in Ru(II)-Dye Sensitized Solar Cells. Chem. Mater. 25, 4497-4502 (2013).

36. Santos, C. M. et al. Pyranoflavylium Derivatives Extracted from Wine Grape as Photosensitizers in Solar Cells. J. Braz. Chem. Soc. 25, 1029-1035 (2014).

37. Zhang, D. et al. Betalain pigments for dye-sensitized solar cells. J. Photochem. Photobiol. A Chem. 195, 72-80 (2008).

38. Qin, C. \& Clark, A. E. DFT characterization of the optical and redox properties of natural pigments relevant to dye-sensitized solar cells. Chem. Phys. Lett. 438, 26-30 (2007). 